\title{
Recovery of Functional Pigments from four Different Species of Microalgae
}

\author{
Marina Stramarkou ${ }^{1}$, Sofia Papadaki ${ }^{1}$, Konstantina Kyriakopoulou ${ }^{1}$, \\ Magdalini Krokida ${ }^{1}$ \\ ${ }^{1}$ Laboratory Of Process Analysis And Design, School Of Chemical Engineering, National Technical University \\ Of Athens, Zografou Campus, Athens, GR-15700, Greece,
}

\begin{abstract}
In the present work, four species of microalgae: Spirulina platensis (SP), Chlorella vulgaris $(C V)$, Haematococcus pluvialis (HP), and the diatom Phaeodactylum tricornutum (PT) were selected as raw materials for the recovery of multifunctional extracts. Ultrasonic assisted extraction (UAE) using different solvents was applied under specific optimized conditions. Organic solvents such as hexane, acetone and ethanol, as well as food grade solvents, such as limonene, MCT oil, soybean oil and phosphate buffer $(p H=7)$ were used. The total carotenoid, $\beta$-carotene and chlorophyll a content in the extracts was determined for all species using UV-Vis spectrometry. Moreover, in the case of SP the phycocyanin content was also measured. The extracts were evaluated regarding their antiradical activity using the DPPH method. Taking into consideration the nature of the solvent used and the total pigment content, acetone and ethanol can be replaced by limonene for the extraction of total carotenoids from HP and PT. For the extraction of phycocyanin from SP, water was considered the most efficient solvent. Ethanol extracts of $C V$ were found rich in $\beta$-carotene. The DPPH assay revealed that HP and PT biomass exhibited the highest antiradical activity which can be recovered using suitable solvents.
\end{abstract}

Keywords: antioxidant activity, carotenoids, chlorophylls, phycocyanin, ultrasound-assisted extraction

\section{Introduction}

Microalgae are microscopic algae that are usually found in the marine systems. They are important photosynthetic microorganisms that have the ability to convert about $10 \%$ of the energy from solar light in chemical energy via photosynthesis. Microalgae contain high protein content, with balanced amino acids pattern, carotenoids, polyunsaturated fatty acids, vitamins, polysaccharides, sterols, phycobilins and other biologically active compounds, more efficiently than traditional crops [1], [2]. Microalgae can be used to enhance the nutritional value of food and animal feed, they play a crucial role in aquaculture and they can be applied into cosmetics. Microalgae can be incorporated into the feed for a wide variety of animals ranging from fish (aquaculture) to pets and farm animals. They are utilized in aquaculture as live feeds for all growth stages of bivalve molluscs (oysters, scallops, clams and mussels), for the larval/early juvenile stages of abalone, crustaceans and some fish species, and for zooplankton used in aquaculture food chains [2], [3]. In addition, they are cultivated as a source of highly valuable molecules. For example, polyunsaturated fatty acid oils are added to infant formulas and nutritional supplements, as well as pigments are important as natural dyes. Microalgae for human nutrition are nowadays marketed in different forms such as tablets, capsules and liquids. Microalgae extracts have also the ability to provide simultaneously several uses (provide high nutrient content, stability and increased properties in colour, texture and emulsification) that enhance the various quality and nutritious aspects, reducing the appropriate enhancers quantity. Some microalgal species' extracts are established in the skin care market, and can be mainly found in face and skin care products (anti-aging cream, refreshing or regenerant care products, emollient, anti-irritant in peelers), sun protection and hair care products [2].

In the present work, four species of microalgae: Spirulina platensis (SP), Chlorella vulgaris (CV), Haematococcus pluvialis (HP) and the diatom Phaeodactylum tricornutum (PT) were selected as raw materials for the recovery of multifunctional extracts. Spirulina is known to have therapeutic properties to diseases such as diabetes, arthritis, anaemia, cardiovascular diseases and cancer due to its rich source in antioxidant compounds (phycocyanin) and nutritious compounds (carotenoids and chlorophylls). It is also used as a functional ingredient into various food products to enhance their nutritional qualities [4]-[6]. Chlorella Vulgaris apart from presenting high contents of proteins (51-58\% dry weight), accumulates severalcarotenoidsIn addition, the alga has beneficial effects in scavenging free radicals and reducing blood lipids [6], [7]. Haematococcus pluvialis (H. pluvialis) is a ubiquitous green alga of the order Volvocales, from the family of Haematococcaceae. H. pluvialis is usually found in temperate regions around the world. The general composition of Haematococcus algae consists of common carotenoids, fatty acids, proteins, carbohydrates, and 
minerals. This species of H. pluvialis is well known for its high content of the strong antioxidant astaxanthin, which is important in aquaculture, various pharmaceuticals, and cosmetics. Haematococcus pluvialis is capable to accumulate large quantities of astaxanthin (0.2-2\% from dry biomass) [8]. Phaeodactylum tricornutum (P. tricornutum) is a diatom and it is the only species in the genus Phaeodactylum. Unlike other diatoms $\mathrm{P}$. tricornutum can exist in different morphotypes (fusiform, triradiate, and oval), and changes in cell shape can be stimulated by environmental conditions [9]. P. tricornutum belongs to the Bacillariophyceae (diatoms), formerly classified as Nitzschia closterium [10]. The most notable characteristic of this strain is its ability to grow to high cell densities, reaching in PUFAs and carotenoids [11], [12]. The presented work aimed to optimize the recovery of bioactive compounds from 4 microalgae species obtaining multifunctional total extracts. Ultrasound assisted extraction was used in optimum extraction conditions in different solvent systems adapted to the extractable substances of each microalgae species. The quality of extracts was evaluated through the determination of total carotenoids, b-carotene, chlorophyll a, phycocyanin and antioxidant activity.

\subsection{Materials}

\section{Materials and Methods}

Microalgae of four different strains were delivered wet or dried in our lab for investigation and were immediately stored at $-30{ }^{\circ} \mathrm{C}$ to avoid degradation. Specifically, Spirulina platensis (SP), Chlorella vulgaris (CV) were collected containing $88.84 \pm 3.30 \%$ and $70.38 \pm 2.90 \%$ moisture content, respectively, while Haematococcus pluvialis (HP) and Phaeodactylum tricornutum (PT) was delivered in the lab in dried powder form containing $3.02 \pm 0.21 \%$ and $2.92 \pm 0.13 \%$ moisture content, respectively.

\subsection{Chemicals}

All reagents and solvents used in the extractions were of analytical grade. 2,2-diphenyl-picrylhydrazyl (DPPH) reagent was purchased from Sigma-Aldrich. Water, ethanol, methanol, hexane, acetone and phosphate buffer were purchased from Fisher scientific (UK). Medium chain triglycerides (MCT), limonene and soybean oil were of food grade.

\subsection{Drying Treatment}

Spirulina Platensis (SP) and Chlorella Vulgaris (CV) were delivered wet and industrial drying as well as hot-air drying were applied, respectively. Concerning industrial drying, SP films of thickness of 1-2 mm were placed on metal tables and remained in a low height greenhouse for three hours at $60^{\circ} \mathrm{C}$. As regards the hot-air drying, the laboratory oven (Binder ED $115,230 \mathrm{~V}, 1,6 \mathrm{KW}$ ) was used at $60^{\circ} \mathrm{C}$ for 12 hours. Thin layers of $1-5$ $\mathrm{mm}$ of $\mathrm{CV}$ wet biomass were placed in the oven on non-stick baking paper.

\subsection{Extraction Experiment}

Ultrasound assisted extractions (UAE) were carried out in an ultrasound bath a XO-SM50 Ultrasonic Microwave Reaction System (Nanjing Xianou Instruments Manufacture co., Ltd., Nanjing City, China). Samples of untreated or dried microalgae were placed in a beaker with $50 \mathrm{~mL}$ in a Solid to Solvent ratio 1:20 grams dry weight per $\mathrm{ml}$ solvent and extracted while operating at $25 \mathrm{kHz}$ frequency, at 450 Watt and temperature $30{ }^{\circ} \mathrm{C}$ for a total duration of $5 \mathrm{~min}$. The solvents used were selected according to the microalgae strain and the bioactive compounds it contains (Table 1).

Table 1. Design of experiment for the different microalgae strains according to the target compounds.

\begin{tabular}{|c|c|c|c|}
\hline Microalgae & Solvents & Extraction conditions & Bioactive compounds \\
\hline Spirulina platensis (SP) & $\begin{array}{l}\text { Water } \\
\text { Hexane } \\
\text { Ethanol }\end{array}$ & $\begin{array}{c}25 \mathrm{kHz} \\
50 \mathrm{ml} \text { of solvent } \\
\text { SP dry weight: } 2,5 \mathrm{~g} \\
450 \mathrm{~W}, 50 \% \mathrm{P} \\
\mathrm{t}=5 \mathrm{~min}\end{array}$ & $\begin{array}{l}\text { Phycocyanin, Carotenoids, } \\
\text { Chlorophylls }\end{array}$ \\
\hline Chlorella vulgaris (CV) & $\begin{array}{l}\text { Buffer } \\
\text { Water } \\
\text { Ethanol }\end{array}$ & $\begin{array}{c}25 \mathrm{kHz} \\
50 \mathrm{ml} \text { of solvent } \\
\text { CV dry weight:2,5 g, } 450 \\
\text { W, 50\%P } \\
\mathrm{t}=5 \mathrm{~min} \\
\end{array}$ & Carotenoids, Chlorophylls, \\
\hline Haematococcus pluvialis (HP) & $\begin{array}{c}\text { Acetone } \\
\text { MCT } \\
\text { Limonene } \\
\text { Soybean oil }\end{array}$ & $\begin{array}{c}25 \mathrm{kHz} \\
50 \mathrm{ml} \text { of solvent } \\
\text { HP dry weight:2,5 g, } 450 \\
\text { W, } 50 \% \mathrm{P} \\
\mathrm{t}=5 \mathrm{~min}\end{array}$ & Carotenoids, Chlorophylls \\
\hline $\begin{array}{l}\text { Phaeodactylum tricornutum } \\
\text { (PT) }\end{array}$ & $\begin{array}{c}\text { Water } \\
\text { MCT } \\
\text { Hexane } \\
\text { Limonene }\end{array}$ & $\begin{array}{c}25 \mathrm{kHz} \\
50 \mathrm{ml} \text { of solvent } \\
\text { PT dry weight:2,5 g, } 450 \\
\text { W, 50\%P } \\
\mathrm{t}=5 \mathrm{~min}\end{array}$ & $\begin{array}{l}\text { Carotenoids, } \\
\text { Chlorophylls }\end{array}$ \\
\hline
\end{tabular}




\subsection{Bioactive Content Evaluation}

\subsubsection{Total Carotenoid and Chlorophyll content}

The total carotenoid and chlorophyll a content was estimated through Jeffrey 1997 protocol (Jeffrey et al. 1997), using $90 \%$ acetone as solvent. The measurements took place at 664, 647, $630 \mathrm{~nm}$ for chlorophylls and 510, $480 \mathrm{~nm}$ for carotenoids. Equation (1) was used for chlorophyll a determination and equation (2) for total carotenoids.

$$
\begin{gathered}
\mathrm{Ca}(\mu \mathrm{g} / \mathrm{L})=11.85(\mathrm{~A} 664)-1.54(\mathrm{~A} 647)-0,08(\mathrm{~A} 630) \\
\mathrm{Cp}(\mu \mathrm{g} / \mathrm{L})=7,60(\mathrm{~A} 480)-1,49(\mathrm{~A} 510)
\end{gathered}
$$

\subsection{2 $\quad \beta$-carotene Content}

The b-carotene content was estimated through Ben Amotz \& Avron 1983 protocol [13] , using 80\% acetone as solvent. The measurements took place at $480 \mathrm{~nm}$.

Where, A: absorbance at $480 \mathrm{~nm}$

$$
\mathrm{C}=\mathrm{A} / \varepsilon \mathrm{l}(\mathrm{mol} / \mathrm{l}))
$$

$\varepsilon$ : coefficient / $\varepsilon=2273$ at $480 \mathrm{~nm}$ for $\beta$-carotene [13]

1: distance traveled by the light beam according to the cuvette used

\subsubsection{Phycocyanin Content}

The phycocyanin content was estimated through Boussiba \& Richmond 1980 protocol [14]using 100 $\mathrm{mM}$ phosphate buffer as solvent. The measurements took place at $620 \mathrm{~nm}$, using the following equation :

C-Phycocyanin $(\mathrm{PC}): \%$ pure C-PC $=[\mathrm{A} 620 \times(10 \mathrm{ml}) \times(100)] / 7.3 \times(\mathrm{mg}$ sample $) \times(\% \mathrm{dw}))$

\subsubsection{Antiradical Activity}

The $\mathrm{A}_{\mathrm{AR}}$ was evaluated with the stable radical 2,2-diphenyl-1-picrylhydrazyl (DPPH) [15] . Briefly, 0.1 $\mathrm{mL}$ of microalgae extracts were added to $3.9 \mathrm{~mL}$ of DPPH $(0.03 \mathrm{mg} / \mathrm{ml})$ in methanol. A Uv-Vis spectrophotometer (Helios Unicam) was used to measure the absorbance at $515 \mathrm{~nm}$ after 30 minutes. The changes in absorbance were measured at $25^{\circ} \mathrm{C}$ for appropriately diluted samples. A calibration curve at $515 \mathrm{~nm}$ was made with DPPH and the percentage of remaining DPPH (\%DPPH rem) was calculated as described from :

$$
\% \mathrm{DPPH} \text { Inhibition }=1-([\mathrm{DPPH} \bullet] \mathrm{t} /[\mathrm{DPPH} \bullet] \mathrm{t}=0) \times 100 \%
$$

\section{Results And Discussion}

The four studied microalgae were selected according to their origin, in order to evaluate the widest categories of microalgae strains on their bioactive potential. Each strain is a different case study, the extractability of bioactive compounds differs among the species, therefore in each case the proper solvents and extraction conditions were selected.

In the case of SP, the majority of bioactive compounds are water-soluble, therefore polar solvents such as water and ethanol were selected in order to show the difference to non-polar solvents such as hexane. Moreover, untreated and dried microalgae were studied on their bioactive potential. Drying affected the content of carotenoids, chlorophylls and phycocyanin. As shown in Table 2, the total carotenoids and chlorophyll a yields of the dried biomass extracted with water and ethanol are higher compared with the wet biomass. This happens because the wet biomass cells contain already high percentages of internal water, which acts competitively with the water as solvent. In other words, the solid-liquid extraction relies on diffusion phenomena and for this reason the aqueous extraction of dry biomass is favoured because of the better diffusion and impregnation of the solvents inside the microalga. In addition, the bioactive content in the extracts of hexane could not be detected using the calibration curve ranging from 0.100 to 1.200 absorbance. This was expected, as hexane is a non-polar solvent. Polar solvents, such as water and ethanol, increase the permeability of the microalga cell wall, increasing thus the extraction yields and the recovery of the functional pigments. Concerning wet biomass, water as polar protic solvent is proved to be optimal for the extraction of bioactive compounds, while ethanol performs better antioxidant activity. On the other hand, ethanol is the most efficient solvent for the extraction of dried biomass, but its antioxidant activity was of medium action. Phycocyanin is a substance in Spirulina that exhibits large industrial interest and ethanol was proved the most efficient solvent for the recovery of phycocyanin in wet biomass, while water had the best results in dried biomass.

In the case of $\mathrm{CV}$, solvents of high polarity, such as water, buffer and ethanol were selected for the recovery of bioactive compounds. As shown in Table 3, untreated and dried microalgae were extracted and the drying seemed to affect significantly the total carotenoids and chlorophylls, showing degradation of the extracts. On the other hand, the antioxidant activity is enhanced showing that Chlorella's antioxidant potential is a product of other bioactive compounds such as phenolics. So, if the aim of the study is the recovery of a large quantity of total carotenoids, chlorophyll a and b-carotene, no drying is needed and ethanol is the optimum 
solvent for the extraction. Concerning dry biomass, whose content in bioactive compounds is degraded, aqueous and buffer extracts show satisfactory results and are the most efficient for food application.

In the case of HP, the dried microalga that was extracted showed high bioactive content, despite the partial stress due to the pre-treatment (Table 4). Extracts proved to have high content in antioxidantive compounds. This antioxidant action is due to both the astaxanthin and the secondary metabolites created during drying. In addition, although HP derived from culture conditions that aimed to large production of astaxanthin, showed significant quantity of chlorophyll a, which was not consumed or destroyed during the pretreatment. Food grade solvents were suggested such as limonene and soy oil for replacing widely used organic solvents such as acetone and hexane. Limonene was found to enhance the recovery of carotenoids due to its lipophilic nature while at the same time retains the antioxidant activity. On the other hand, limonene shows low selectivity regarding the chlorophylls, therefore it is suggested for the recovery of extracts of high purity in carotenoids, which can be used as natural food enhancers. In case that the chlorophylls are the targeted compounds semipolar solvents such as acetone are suggested. Comparing the different solvents, soy oil shows the highest antioxidant activity, reaching $100 \%$, and the highest recovery of astaxanthin, which is the principal carotenoid in HP. The high antioxidant capacity is explained by the fact that the soy oil used in the experiments was of food grade, so it was enriched with natural antioxidants that prevent the oxidative rancidity. In addition, soy oil has a typical golden color and absorbs near the absorption range of carotenoids, creating coating phenomena.

Finally, in the case of PT, the total carotenoid and chlorophyll content was particularly high (Table 5). By using food grade solvents (especially limonene) the extraction of total carotenoids is enhanced while at the same time exhibits high antioxidant potential. In addition, PT aqueous extracts showed high chlorophyll content and the highest antioxidant activity. Hexane is considered inappropriate solvent because of its petrochemical origin, on the one hand, which prohibits the application of the diatom PT in the food industry, and because of the moderate yields it achieves, on the other hand. In addition, the major carotenoid in PT is fucoxanthin and this fact explains the low percentage of $b$-carotene in total carotenoids.

Table 2. Bioactive content of Spirulina platensis (SP) extracts.

\begin{tabular}{|l|l|l|l|l|l|l|}
\hline Sample & Extract & $\begin{array}{l}\text { Total carotenoids } \\
(\mathbf{m g} / \mathbf{g}) \text { dry base }\end{array}$ & $\begin{array}{l}\text { Chlorophyll a } \\
(\mathbf{m g} / \mathbf{g}) \text { dry base }\end{array}$ & $\begin{array}{l}\text { Phycocyanin } \\
\text { \% dry base }\end{array}$ & $\begin{array}{l}\text { b-carotene }(\mathbf{m g} / \mathbf{g}) \\
\text { dry base }\end{array}$ & $\begin{array}{l}\text { \% Inhibition of } \\
\mathbf{0 , 1} \text { ml extract }\end{array}$ \\
\hline Wet & Water & 28.52 & 59.01 & 0.46 & 6.07 & 11.62 \\
\hline Dried & Water & 50.55 & 86.95 & 3.22 & 8.18 & 46.78 \\
\hline Wet & Hexane & N.D. & N.D. & N.D. & N.D. & 3.78 \\
\hline Dried & Hexane & N.D. & N.D. & N.D. & N.D. & 1.42 \\
\hline Wet & Ethanol & 21.09 & 23.26 & 2.71 & 3.60 & 22.79 \\
\hline Dried & Ethanol & 46.50 & 89.81 & 0.02 & N.D. & 4.16 \\
\hline
\end{tabular}

Table 3. Bioactive content of Chlorella vulgaris (CV) extracts.

\begin{tabular}{|l|l|l|l|l|l|}
\hline Sample & Extract & $\begin{array}{l}\text { Total } \\
\text { carotenoids } \\
(\mathbf{m g} / \mathbf{g}) \text { dry base }\end{array}$ & $\begin{array}{l}\text { Chlorophyll a } \\
(\mathbf{m g} / \mathbf{g}) \text { dry base }\end{array}$ & $\begin{array}{l}\text { b-carotene } \\
(\mathbf{m g} / \mathbf{g}) \text { dry } \\
\text { base }\end{array}$ & $\begin{array}{l}\text { \% Inhibition } \\
\text { of 0.1 ml } \\
\text { extract }\end{array}$ \\
\hline Wet & Buffer $\mathrm{pH}=7$ & 42.06 & 26.92 & 1.88 & 18.41 \\
\hline Dried & Buffer $\mathrm{pH}=7$ & 77.81 & 25.48 & 3.19 & 40.18 \\
\hline Wet & Water & 70.97 & 36.92 & 2.77 & 24.13 \\
\hline Dried & Water & 104.66 & 35.19 & 3.27 & 11.64 \\
\hline Wet & Ethanol & 427.10 & 351.00 & 19.46 & 2.89 \\
\hline Dried & Ethanol & 16.05 & 8.17 & 2.44 & 4.26 \\
\hline
\end{tabular}

Table 4. Bioactive content of Haematococcus pluvialis (HP) extracts.

\begin{tabular}{|l|l|l|l|l|}
\hline Extract & $\begin{array}{l}\text { Total carotenoids } \\
(\mathbf{m g} / \mathbf{g}) \text { dry base }\end{array}$ & $\begin{array}{l}\text { Chlorophyll a } \\
(\mathbf{m g} / \mathbf{g}) \text { dry base }\end{array}$ & $\begin{array}{l}\text { Astaxanthin } \\
(\mathbf{m g} / \mathbf{g}) \text { dry base }\end{array}$ & $\begin{array}{l}\text { \% Inhibition of 0.1 } \\
\text { ml extract }\end{array}$ \\
\hline Acetone & 8.05 & 17.55 & 5.61 & 52.81 \\
\hline MCT & 5.05 & 1.05 & 1.74 & 24.02 \\
\hline Limonene & 36.10 & 5.04 & 5.23 & 61.98 \\
\hline Soy oil & 28.04 & 1.58 & 10.66 & 100.00 \\
\hline
\end{tabular}

Table 5. Bioactive content of Phaeodactylum tricornutum (PT) extracts.

\begin{tabular}{|l|l|l|l|l|}
\hline Extract & $\begin{array}{l}\text { Total carotenoids } \\
(\mathbf{m g} / \mathbf{g}) \text { dry base }\end{array}$ & $\begin{array}{l}\text { Chlorophyll a } \\
(\mathbf{m g} / \mathbf{g}) \text { dry base }\end{array}$ & $\begin{array}{l}\text { b-carotene (mg/g) } \\
\text { dry base }\end{array}$ & $\begin{array}{l}\text { \% Inhibition of 0.1 } \\
\text { ml extract }\end{array}$ \\
\hline Water & 43.82 & 24.37 & 1.39 & 88.41 \\
\hline MCT & 30.82 & 3.98 & 0.49 & 1.76 \\
\hline Limonene & 84.84 & 19.70 & 1.41 & 57.97 \\
\hline Hexane & 20.97 & 3.25 & 0.09 & 2.03 \\
\hline
\end{tabular}




\section{Conclusion}

Microalgae consist a rich source of bioactive substances with a wide range of applications and can produce high added value products with the appropriate treatment. Depending on the type and the family to which they belong, and the conditions in which they have grown, microalgae show significant differences in their structure, quality characteristics, extractability and bioactive ingredients. Therefore, the need to develop procedures for determining the bioactive components of each microalga and to facilitate the extraction of targeted substances is emerging.

Drying is considered a required pre-treatment step as the moisture content of the microalgae ranges from $90-95 \%$ after harvesting. Dried microalgae biomass can be used as it is for various applications or can be further processed in order to obtain high added value products in the form of extracts. However, drying can affect the bioactive content of the algae and therefore the extraction selectivity.

The selection of the appropriate extraction method is based on the environmental friendliness and the applicability in industrial scale. The ultrasonic extraction meets these criteria, since it is an efficient, economical and industrially applicable process which recovers a high proportion of the bioactive content. The high efficiency of the extraction was maintained even with the application of mild solvents, which can be incorporated into food systems, such as vegetable oils, essential oils and aqueous systems, answering to the global trend towards green process and environmental friendly products.

This research shows the importance of microalgae as natural sources of bioactive compounds, which can be recovered using green extraction processes. For further research we propose the optimization of other extraction techniques, such as microwave, supercritical extraction, etc., and the validation of more methods for the characterization of the extracts, such as high-performance liquid chromatography (HPLC).

[1]. W. Becker, Microalgae in Human and Animal Nutrition. 2004.

\section{References}

[2]. P. Spolaore, C. Joannis-Cassan, E. Duran, and A. Isambert, "Commercial applications of microalgae.," J. Biosci. Bioeng., vol. 101, no. 2, pp. 87-96, Feb. 2006.

[3]. M. R. Brown, "Nutritional Value and Use of Microalgae in Aquaculture," in Avances en Nutricion Acuicola, 2002.

[4]. C. V. Seshadri, B. V. Umesh, and R. Manoharan, "Beta-carotene studies in Spirulina," Bioresour. Technol., vol. 38, no. 2-3, pp. 111-113, Jan. 1991.

[5]. H. Shimamatsu, "Mass production of Spirulina, an edible microalga," Hydrobiologia, vol. 512, no. 1-3, pp. 39-44, 2004.

[6]. M. K. Ü. Nal, "Biomass Nutrient Profiles of Three Microalgae : Spirulina platensis , Chlorella vulgaris , and Isochrisis galbana," vol. 68 , no. $4,2003$.

[7]. A. C. Guedes, H. M. Amaro, and F. X. Malcata, "Microalgae as sources of carotenoids.," Mar. Drugs, vol. 9, no. 4, pp. 625-44, Jan. 2011.

[8]. G. A. Ravishankar, S. M. Arad, K. N. Chidambara Murthy, P. Galaup, L. Dufossé, A. Yaron, and P. Blanc, "Microorganisms and microalgae as sources of pigments for food use: a scientific oddity or an industrial reality?," Trends in Food Science \& Technology, vol. 16. pp. 389-406, 2005.

[9]. A. De Martino, A. Meichenin, J. Shi, K. Pan, and C. Bowler, "Genetic and phenotypic characterization of Phaeodactylum tricornutum (Bacillariophyceae) accessions 1,” J. Phycol., vol. 43, pp. 992-1009, 2007.

[10]. J. C. LEWIN, R. A. LEWIN, and D. E. PHILPOTT, "Observations on Phaeodactylum tricornutum.," J. Gen. Microbiol., vol. 18, pp. 418-426, 1958.

[11]. W. Yongmanitchai and O. P. Ward, "Growth of and omega-3 fatty acid production by Phaeodactylum tricornutum under different culture conditions.," Appl. Environ. Microbiol., vol. 57, no. 2, pp. 419-25, Feb. 1991.

[12]. P. Pérez-López, S. González-García, C. Allewaert, A. Verween, P. Murray, G. Feijoo, and M. T. Moreira, "Environmental evaluation of eicosapentaenoic acid production by Phaeodactylum tricornutum.," Sci. Total Environ., vol. 466-467C, pp. 991-1002, Aug. 2013.

[13]. a Ben-Amotz and M. Avron, "On the Factors Which Determine Massive beta-Carotene Accumulation in the Halotolerant Alga

[14]. S. Boussiba and A. E. Richmond, "C-phycocyanin as a storage protein in the blue-green alga Spirulina platensis," Arch. Microbiol., vol. 125, no. 1-2, pp. 143-147, 1980.

[15]. K. Kyriakopoulou, A. Pappa, M. Krokida, A. Detsi, and P. Kefalas, "Effects of Drying and Extraction Methods on the Quality and Antioxidant Activity of Sea Buckthorn (Hippophae rhamnoides) Berries and Leaves.," Dry. Technol., vol. 31, no. 9, pp. 1063-1076, 2013. 